\title{
Construction and Analysis of Governance Evaluation Index System of Beijing Urban Subcenter Based on System Theory and Information Theory
}

\author{
Liexuan Wang ${ }^{\mathbb{D}},{ }^{1}$ Kunsheng Wang, ${ }^{1}$ and Huajin Huang ${ }^{2}$ \\ ${ }^{1}$ China Aerospace Academy of Systems Science and Engineering, Beijing 100048, China \\ ${ }^{2}$ Communication University of China, Beijing 100048, China
}

Correspondence should be addressed to Liexuan Wang; wangliexuan2022@163.com

Received 4 January 2022; Revised 19 January 2022; Accepted 22 January 2022; Published 10 February 2022

Academic Editor: Kalidoss Rajakani

Copyright (C) 2022 Liexuan Wang et al. This is an open access article distributed under the Creative Commons Attribution License, which permits unrestricted use, distribution, and reproduction in any medium, provided the original work is properly cited.

\begin{abstract}
The construction of subcenters is considered an effective measure to solve the diseases in big cities and improve urban competitiveness. China takes the planning and construction of the Beijing urban subcenter as a major national decision-making deployment. Therefore, the establishment of a scientific and reliable evaluation index system for the urban subcenter is of great significance to the public sector to diagnose urban problems and improve urban performance management. Under the guidance of system theory, this paper establishes the governance evaluation index system of the Beijing subcenter based on the five subsystems: economic subsystem, social subsystem, cultural subsystem, ecological subsystem, and administrative subsystem, and 29 secondary indicators. After comprehensively examining the panel data of the overall Beijing urban system during the construction of the subcenter (2010-2019), the entropy method is used to objectively assign the value of the Beijing urban subcenter (Tongzhou District), and it is compared with other 15 municipal districts. The derivation of the development dynamic evolution of the Beijing urban subcenter is completed through the geospatial visualization and the linear regression fitting. It is found that the comprehensive index of urban subcenter governance in Beijing shows an upward trend year by year and has developed by leaps and bounds under the promotion of the central policy. Driven by Beijing's subcenter strategy, the development model of the whole of Beijing has moved from a typical center diffusion model to a dual center to a subcenter and even a diversified development pattern. This paper proposes to lead urban development with the concept of high-quality development, adhere to innovation-driven, improve urban comprehensive carrying capacity through urban software and hardware construction, and realize regional coordinated development on a larger spatial scale.
\end{abstract}

\section{Introduction}

Urbanization is a remarkable feature of the 21st century. Urbanization has not only brought about a higher quality of life but also brought about serious big city diseases. The construction of the subcenter is considered to be an effective measure to solve the problems of big cities [1]. China regards the planning and construction of the Beijing subcenter as a major national decision and deployment. The CPC Central Committee with Comrade Xi Jinping as the core has continuously promoted the planning and deployment of the Beijing subcenter since the 18th National Congress of the CPC. On November 26, 2021, the State Council issued the opinions on supporting the high-quality development of the Beijing urban subcenter, symbolizing that the construction of the Beijing urban subcenter has entered a new stage. Promoting the high-quality development of Beijing urban subcenter objectively requires the establishment of a scientific and reasonable evaluation index system. We should understand and evaluate the construction of Beijing urban subcenter, truly reflect the development progress and improvement direction, and finally establish a performance management system based on the evaluation index system. Therefore, it is necessary and urgent to carry out a systematic, scientific, and feasible evaluation of the high-quality development of the Beijing urban subcenter. 
Most of the existing studies on the evaluation index system of Beijing urban subcenter use the subjective evaluation methods, such as brainstorming, Delphi method (brainstorming and Delphi method), and the fuzzy comprehensive evaluation theory [2] to construct the evaluation system from the perspective of influencing factors. This paper holds that the Beijing urban subcenter is an open complex giant system. It is of great significance to establish the governance evaluation index system of Beijing urban subcenter based on the system theory and from the perspective of urban governance. At the same time, in the process of establishing the evaluation index system, it is necessary to introduce more methods based on objective data, informatics, and physical principles to increase scientificity. Therefore, this paper establishes the governance evaluation index system of the Beijing subcenter based on the five subsystems: economic subsystem, social subsystem, cultural subsystem, ecological subsystem, and administrative subsystem, and 29 secondary indicators. According to the definition of information entropy in Shannon \& Weaver's information theory, the entropy method is used to objectively assign the value of Beijing urban subcenter (Tongzhou District), and compared with the other 15 municipal districts. The development dynamic evolution of the Beijing urban subcenter is deduced through the geospatial visualization and the linear regression fitting. This paper attempts to draw the dynamic map of Beijing urbanization before and after the implementation of the subcenter strategy, which analyzes and forecasts the exogenous impact of the national strategy on the urban subcenter, and finally gives the overall ideas and suggestions to strengthen the governance of Beijing urban subcenter according to the relevant research.

\section{Connotation and System Characteristics of the Beijing Subcenter Governance Based on the System Theory}

In 1999, UN-Habitat launched the Global Urban Governance Campaign with the goal of "Sustainable Human settlements Development in an urbanized World," aiming to achieve the goal of poverty eradication and prosperity of cities through improved urban governance. $\mathrm{Yu}$, editor of the book, Governance and Good Governance System, introduces Stoker, Koeman, and Rose's theories of governance, such as representative of ideas. He defined the meaning of "governance" using the western meaning of the theory. His theory contains the essence of good governance in which the connotation is: multivariate main body participation and interaction based on market principles, management mechanism based on mutual recognition and public interest. Since then, Chinese scholars have carried out application researches of governance theory in different fields based on this concept. Based on the above connotations of urban governance and guided by the thought of system theory, this paper holds that urban governance is a complex system engineering composed of three elements, namely, the subject of urban governance, the object of urban governance, and the external environment of urban governance. Therefore, the governance of Beijing city sub-center is a complex system engineering that takes the Beijing city subcenter as the governance object. It also takes the good governance as the realization goal.

The application of the system theory to urban governance evaluation should be based on a comprehensive analysis of the complex system of urban governance. The complexity of urban governance in China is reflected in the complexity of the system structure and evolution law of the object of urban governance. The complexity of the multiple demands of the main body of urban governance and the complexity of the realization of urban governance functions are analyzed. From the perspective of the characteristics of the Beijing subcenter system, it is embodied in the typical external intervention force drive, government-led development path, and quality pilot requirement constraints. Therefore, from the perspective of the purpose of the system proposed by Aristotle, which laid the foundation of the logical framework of system theory, namely, the realization of functions, this paper proposes that the analysis of urban governance system under the guidance of system theory should be based on five subsystems, which include economic system, social system, cultural system, ecological system, and administrative system. The economic system includes the wealth creation ability of residents, the upgrading of industrial structure, the scale and production capacity of industrial enterprises, and the connection between the economic system and other systems. The social system includes the stable situation of population size, the quality of life of residents, the social medical security resources and the degree of further development, construction, and improvement of the infrastructure. The cultural system includes the intensity of regional investment in innovation capacity, the historical and cultural competence, and education development. The ecological system includes the pollution degree of industrial waste to the environment and the ecological environment purification capacity. The administrative system includes the degree of specialization of government administration and the level of public finance.

And, the five subsystems have their unique basic characteristics, functional state, and operation trend. The reason is that the five subsystems are determined by the nature, quantity, and relationship of elements. In the process of movement, each subsystem is decomposed into different elements [1]. The optimization of each element and the improvement of the interaction relationship promoted the evolution of the subsystem to a higher level system. Based on the holistic thinking of the system theory, to maximize the overall benefits after the optimal combination of subsystems, it is necessary to use the quantitative analysis method to put the five subsystems as a part of the complex giant system into the overall system for analysis and evaluation. Thus, the important difference of each subsystem in the development of the complex giant system and the short board of subsystem development in the system interaction environment is found, and the promotion path of elements and subsystems is put forward. 


\section{Construction of Governance Evaluation Index System of Beijing Urban Subcenter Based on System Governance}

In order to establish an integrated evaluation index system, on the basis of system theory, we also need to develop a leading macro theoretical framework combined with urban governance theory. Urban governance theory also regards the city as a complex system. Therefore, we can seek the public value and core goal of Beijing urban subcenter governance on its basis.

3.1. Analysis and Reference of Relevant Evaluation Index System in China and Abroad. The theoretical basis of urban governance lies in the governance theory. Many scholars and organizations have constructed corresponding indicators under the guidance of the governance theory. For example, in 1989, the World Bank proposed six world governance indicators, including "accountability, political instability, government efficiency, regulatory burden, rule of law and corruption," centering on the political democratic requirements of the generation and operation of governance power [3]. Yu proposed 12 indicators to measure the level of comprehensive governance in China based on western experience and the characteristics of China's reform and the opening up practice, which can be summarized into four dimensions: "social stability, respect for human rights, public service and government transparency" [4]. Zhang et al. proposed the perspective of urban governance subject government. Indicators are constructed to evaluate the maturity of digital city governance in 31 provinces and cities in China in 2007 from the two levels of reflecting the policy environment of digital city construction from the aspects of talents, government transparency, and regional economic foundation of digital governance and the penetration rate of Internet and digital TV [5]. Guo and Cheng conducted a quantitative study on the level of urban governance for the first time. Based on the goal of multi-subject participation and good governance, they constructed a total of 76 indicators from seven dimensions of participation, fairness, effectiveness, regulation, transparency, honesty, and rule of law. The index calculation and comparative analysis of Beijing, Chengdu, Shanghai, Shenzhen, and Changsha were carried out by using the data of objective statistical yearbook and questionnaire survey results [6]. Lin and Mao, from the perspective of fiscal expenditure performance, conducted an empirical analysis on urban governance performance of urban agglomerations above prefecture-level in Jiangsu and Zhejiang and found that fiscal expenditure in big cities showed diminishing returns to scale in both hard and soft infrastructure [7]. Wang and Xia constructed 49 secondlevel indicators including culture and education, environmental protection, medical and health care, landscaping, infrastructure, and social security from the functional perspective of government providing public goods based on public management theory. Data of Wuhan, Shenzhen, Nanjing, Xi'an, and Shenyang from 2012 to 2014 were selected to conduct comparative analysis and evaluation on the stability, legitimacy, and effectiveness of the urban government governance model [8]. Han et al. collected data from 1990 to 2010 in Shanghai from three dimensions of social economy, geographical space, and community survey by combining subjective and objective methods, and analyzed and evaluated the spatial distribution and temporal evolution characteristics of life quality in Shanghai during the past 20 years [9]. Wang et al. used the Pandora model to evaluate the spatial distribution of green space area in Tongzhou, the subcenter of Beijing, taking land use and environment as parameters [10]. Shen et al. based on the concept of scientific and technological quality development selected five-dimensional indicators to quantitatively evaluate the high-quality development of national central cities in China, including basic support ability, original innovation ability, commanding height possession ability, voice and leadership, and social benefits, so as to obtain high-quality development suggestions of central cities and promote economic and social development [11].

It can be seen that related studies on urban governance evaluation in the early stage mainly focused on comparing and evaluating the governance levels of different cities through urban social public service quality evaluation and government efficiency, while the index system constructed in the later stage has more dimensions and strong practicality, providing a reference for the selection of index ideas for this study. From the perspective of research objects, most of the existing studies are comparative analyses at the level of urban governance in national central cities, while few evaluate and analyze the level of governance in urban subcenters, which has relatively new connotations and functions. This paper takes the Beijing subcenter governance system as the core, puts it in a higher level system of Beijing to evaluate and analyze its governance level with other Beijing urban systems that interact with each other to get the advantages and disadvantages of the Beijing subcenter governance with five system characteristics, to make it better serve China's national development strategy, local government decision-making, and market development needs. Compared with previous studies, the idea of index construction in this paper is unique, which is to provide new ideas and methods for the evaluation of the urban governance level.

3.2. Construction of Governance Evaluation Index System of Beijing Urban Subcenter. Based on the subsystem understanding of the Beijing subcenter governance under the guidance of system theory, this paper constructs the evaluation index system of the Beijing subcenter governance following the principles of value guidance, scientific reliability, data availability, and applicable comparability. The specific ideas of construction are shown in Figure 1.

The value goal of urban governance is recognized as the realization of "good governance," and its foothold is to realize the all-around development of people, which should be based on the people-oriented governance concept first. Therefore, under the background of China's "five-in-one" overall layout and new development concept, it is necessary 


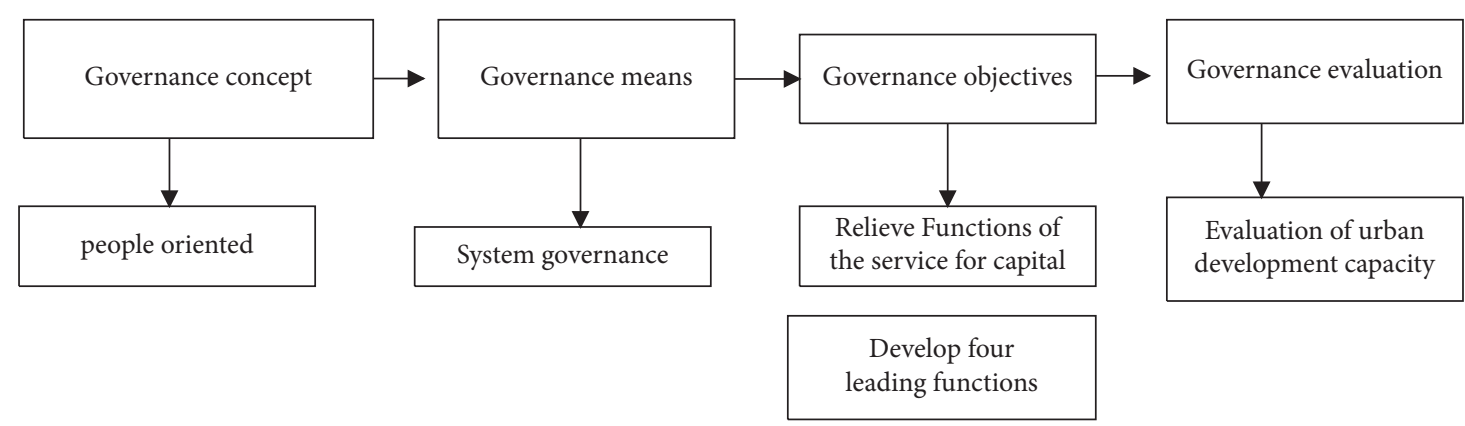

FIgURE 1: Thinking diagram for the construction of governance evaluation index system of the Beijing subcenter.

to create a good living and working environment for citizens. Therefore, system governance is adopted under the system theory guidance. The guidance of system theory is adopted to analyze the five systems of administration, economy, culture, society, and ecological civilization with system thinking as a whole. Thirdly, in order to realize the modernization of national governance system and governance capacity and the key task of building a world-class city in Beijing, the construction of Beijing Urban sub center should aim at serving the four leading functions of the capital. Finally, it is also necessary to evaluate the urban development capacity under the requirements of urban development objectives to find the deficiencies of urban governance.

\subsubsection{Construction Principle.}

(1) The index system is practical. Firstly, the connotation of the index is clear, which can directly reflect the requirements of the basic positioning. The index system can completely and comprehensively serve the goal of the evaluation practice. Secondly, there is a weak correlation between indicators in statistical characterization [12], which can ensure the representativeness of the information provided and avoid duplication.

(2) Indicators should have practical operability. This includes whether the selected data are available and whether there is sufficient time, effort, and funding to obtain the real data.

(3) Indicators are comparable. The selection of indicators needs to be longitudinally compared within the time range of the study, and also has the significance of horizontal comparison with other research individuals. Therefore, the absolute value index and the relative ratio value index should be comprehensively considered in the selection of indicators.

3.2.2. Construction of Index System. According to the construction ideas and principles of the index system, taking the measuring of the development capacity of the object of urban governance as the indicator, this paper constructed 29 secondlevel indicators under the five first-level indicators (Table 1).

The efficiency and quality of the development of the economic subsystems provide basic material support for the development of other subsystems. Therefore, the following indicators that are positively related to the evaluation of the development level of economic subsystem are selected: A1 is the per capita regional GDP, reflecting the wealth creation ability of residents in this region; $\mathrm{A} 2$ is the proportion of tertiary industry in GDP, which is a recognized measurement variable for the upgrading of industrial structure and reflects the quality of regional economic development; A3 is the assets of industrial enterprises above designated size, reflecting the scale and production capacity of industrial enterprises in this region; A4 is the decrease rate of energy consumption per ten thousand yuan of GDP, reflecting the coordination degree of regional economic subsystem with social and ecological subsystem; A5 is the per capita RMB personal savings deposit of Chinese banks, reflecting the income level of local residents and the financial supportability of economic subsystem development; A6 is the growth rate of infrastructure investment, reflecting the strength of sustained economic development to support the development of culture, society, ecological civilization, and administrative system.

The development goal of the social subsystem is to provide a good living social environment and promote the sustainable development of the society, which is an important support for the region to maintain the attractiveness of the population. The following indicators are selected that are positively related to the evaluation of the development level of the social subsystem: B1 is the annual average population, reflecting the stable situation of population size; B2 is the proportion of total retail sales of consumer goods in GDP, reflecting the quality of life of residents in this region; B3 is the average salary of employees on the job, reflecting the actual sense of gain of residents in this area; B4 is the number of hospital beds per 10,000 people; B5 is the number of professional (assistant) doctors per 10,000 people, both of which reflect the richness of social medical security resources in this region; B6 is the ratio of the number of urban employees participating in the basic endowment insurance to the average number of employees on the job in urban units, reflecting the level of coverage breadth of the old-age security level in this region; B7 is the amount of infrastructure investment, which reflects the degree of further development, construction, and improvement of the infrastructure of other subsystems provided by the social system.

The development of the cultural subsystem is mainly to meet people's higher spiritual and cultural needs, prepare for 
TABLE 1: Governance evaluation index system of Beijing urban subcenter.

\begin{tabular}{|c|c|c|c|c|c|}
\hline & Primary index & Secondary index & Code & $\begin{array}{l}\text { Index } \\
\text { nature }\end{array}$ & Impact \\
\hline \multirow{29}{*}{$\begin{array}{l}\text { Evaluation index system of } \\
\text { governance of Beijing urban } \\
\text { subcenter }\end{array}$} & \multirow{7}{*}{$\begin{array}{c}\text { Economic } \\
\text { subsystem (A) }\end{array}$} & Per capita regional GDP (10000 yuan) & A1 & Quantitative & + \\
\hline & & Proportion of tertiary industry in GDP (\%) & A2 & Quantitative & + \\
\hline & & $\begin{array}{l}\text { Assets of industrial enterprises above designated size } \\
\text { (10000 yuan) }\end{array}$ & A3 & Quantitative & + \\
\hline & & $\begin{array}{c}\text { Decline rate of energy consumption of } 10000 \text { yuan } \\
\text { regional GDP (\%) }\end{array}$ & A4 & Quantitative & + \\
\hline & & $\begin{array}{l}\text { RMB personal savings deposits of Chinese funded } \\
\text { banks per capita ( } 10000 \text { yuan) }\end{array}$ & A5 & Quantitative & + \\
\hline & & Growth rate of infrastructure investment (\%) & A6 & Quantitative & + \\
\hline & & Annual average population (10000) (b) & $\mathrm{B} 1$ & Quantitative & + \\
\hline & \multirow{5}{*}{ Social subsystem (B) } & $\begin{array}{l}\text { Proportion of total retail sales of social consumer } \\
\text { goods in GDP (\%) }\end{array}$ & $\mathrm{B} 2$ & Quantitative & + \\
\hline & & Average wage of on-the-job employees (yuan) & B3 & Quantitative & + \\
\hline & & Hospital beds per 10000 people (PCs) & B4 & Quantitative & + \\
\hline & & $\begin{array}{c}\text { Number of licensed (assistant) doctors per } 10000 \\
\text { people (person) }\end{array}$ & B5 & Quantitative & + \\
\hline & & $\begin{array}{l}\text { Ratio of the number of urban employees participating } \\
\text { in basic old-age insurance to the average number } \\
\text { (person) of on-the-job employees in urban units (\%) }\end{array}$ & B6 & Quantitative & + \\
\hline & \multirow{6}{*}{$\begin{array}{l}\text { Cultural subsystem } \\
\text { (C) }\end{array}$} & Infrastructure investment (100 million yuan) & B7 & Quantitative & + \\
\hline & & Proportion of education expenditure in GDP (\%) & $\mathrm{C} 1$ & Quantitative & + \\
\hline & & $\begin{array}{l}\text { Proportion of R\&D internal expenditure ( } 10000 \\
\text { yuan) to GDP ( } 100 \text { million yuan) (10000 ratio) }\end{array}$ & $\mathrm{C} 2$ & Quantitative & + \\
\hline & & Book collection of public libraries (10000 volumes) & $\mathrm{C} 3$ & Quantitative & + \\
\hline & & Number of museums in the cultural relics system & $\mathrm{C} 4$ & Quantitative & + \\
\hline & & Museum visits within the heritage system (thousands) & $\mathrm{C} 5$ & Quantitative & + \\
\hline & \multirow{5}{*}{$\begin{array}{c}\text { Ecosystem } \\
\text { subsystem (D) }\end{array}$} & $\begin{array}{c}\text { Annual average concentration of inhalable fine } \\
\text { particles }(\mu \cdot \mathrm{g} / \mathrm{m} 3)\end{array}$ & D1 & Quantitative & - \\
\hline & & $\begin{array}{l}\text { Centralized treatment rate of sewage treatment plant } \\
(\%) \text { (sewage discharge treatment rate) }\end{array}$ & D2 & Quantitative & + \\
\hline & & Average annual concentration of sulfur dioxide $\left(\mathrm{SO}_{2}\right)$ & D3 & Quantitative & - \\
\hline & & $\begin{array}{l}\text { Average annual concentration of nitrogen dioxide } \\
\qquad\left(\mathrm{NO}_{2}\right)\end{array}$ & D4 & Quantitative & - \\
\hline & & $\begin{array}{l}\text { Fine particulate matter (PM25) annual average } \\
\text { concentration }\end{array}$ & D5 & Quantitative & - \\
\hline & \multirow{6}{*}{$\begin{array}{l}\text { Administration } \\
\text { subsystem (E) }\end{array}$} & Forest greening rate $(\%)$ & D6 & Quantitative & + \\
\hline & & $\begin{array}{c}\text { Per capita local general public budget income (100 } \\
\text { million yuan) }\end{array}$ & E1 & Quantitative & + \\
\hline & & & $\mathrm{E} 2$ & Quantitative & + \\
\hline & & $\begin{array}{l}\text { Proportion of local general public budget deficit (\%) } \\
\text { Ratio of the number of registered unemployed }\end{array}$ & E3 & Quantitative & + \\
\hline & & $\begin{array}{l}\text { persons in cities and towns (actual at the end of the } \\
\text { year) to the number of employees (\%) }\end{array}$ & $\mathrm{E} 4$ & Quantitative & - \\
\hline & & $\begin{array}{c}\text { Number of industrial enterprises above designated } \\
\text { size }\end{array}$ & e5 & Quantitative & + \\
\hline
\end{tabular}

the cultivation of high-quality urban construction talents, and provide a good soft environment of talents and technology for the innovation and improvement of urban governance capacity. Therefore, the following positive correlation indicators are selected. $\mathrm{C} 1$ is the proportion of education expenditure in GDP, reflecting the regional investment in and emphasis on education development. C2 represents the proportion of internal $R \& D$ expenditure in GDP, reflecting the intensity of regional investment in innovation capacity. C3 is the volume of books in public libraries, which reflects the supporting force of the material basis of cultural environment construction. $\mathrm{C} 4$ is the number of museums in the cultural relic system, reflecting the richness and preservation of historical and cultural resources in this region. $\mathrm{C} 5$ is the number of museum visitors in the cultural heritage system, which directly reflects the historical and cultural competence of the region.

The development of the ecological subsystem requires the creation of a natural environment for sustainable development. The following measurement indexes are selected: D1 is the annual average concentration of inhalable fine particles, which directly reflects the quality of the living environment that affects the health of residents, and the indicator negatively affects the evaluation of the 
development level of the ecosystem. D2 is the centralized treatment rate of sewage treatment plants, reflecting the strength of sewage discharge capacity and effect, and positively affecting the level of ecosystem development. D3, D4, and D5 are the annual average concentrations of sulfur dioxide, nitrogen dioxide, and fine particulate matter, respectively, reflecting the pollution degree of industrial waste to the environment and negatively correlated with the evaluation of the ecosystem level. D6 is the rate of tree greening, which reflects the ecological environment purification capacity of the region and is positively correlated with the level evaluation of ecological subsystems.

The administrative management subsystem reflects the strength of the government's governance ability. The following measurement indicators are selected, among which E4 is related to the evaluation of the level of urban governance, while other indicators have a positive impact: E1 is the per capita local general public budget revenue, reflecting the ability of administrative management to support the source of funds; E2 is the per capita expenditure of local general public budget, which reflects the strength of administrative support to the development of other subsystems. E3 is the proportion of the local general public budget deficit, which reflects the excess contribution level of public budget funds of the administrative system to local economic development. E4 is the ratio of registered unemployed persons to employed persons in urban areas at the end of the year, reflecting the inadequacy of the administrative system in promoting employment. E5 is an industrial enterprise above scale, which indirectly reflects the attractiveness of the construction of the business environment in this region to the production of economic units.

\section{Evaluation and Analysis of Governance of Beijing Urban Subcenter Based on the Information Theory}

\subsection{Description of Data Source and Evaluation Method.} To analyze and comprehensively compare the evolution of Beijing's urban subcenter over the years, this paper constructed panel data, which were selected from the regional span of 16 municipal districts in Beijing and the time span from 2010 to 2019. The source of the original data was Beijing Regional Statistical Yearbook from 2010 to 2019, and the time-series panel data used in the final analysis was calculated and sorted out according to the specific connotation of the indicators. According to the Beijing Sub-Urban Center Expansion Area Plan (2016-2035) specially formulated by Beijing Municipal Government, Beijing sub-urban center is the core of Tongzhou District in terms of function. At the same time, Tongzhou District also gives overall consideration to the industrial layout and functional improvement of the expansion area. Considering the data availability, this paper uses the data of Tongzhou District to measure the development of Beijing sub-urban center in a wider range in the future.

Multi-index comprehensive evaluation generally includes principal component analysis, expert scoring method, and the entropy value method. Compared with other methods, the entropy value method applies not only to deal with the data of dimension and the order of magnitude difference characteristics but also can avoid the principal component analysis' impact on the integrity of the data information as well as the expert method's shortcomings of subjective bias [2]. Thus, the evaluation results have more objective credibility. In this paper, the entropy method is used to objectively assign weights. The principle of the assignment is that the greater the variation degree of the practical sequence of a certain data, the smaller the entropy value, indicating that the greater the amount of information contained, the larger the determined weight coefficient [13]. After calculating the corresponding weight matrix, the corresponding score will be obtained. Specific methods are divided into the following steps:

Step 1. Considering that the overall period of the data is 10 years, it is stipulated in the calculation that $x_{i j k}(i=1,2,3,10 ; j=1,2,3,16 ; k=1,2,3,29)$, which represents the value of the $i$-th year, the $j$-th municipal district, and the $k$-th indicator, where the value ranges of $i, j$, and $k$ are from $1-10,1-16$, and $1-29$, respectively.

Step 2. Standardized treatment of various indicators. $x_{\min k}$ and $x_{\max k}$ are the minimum value and maximum value of the $k$-th indicator, respectively. The processing method of the positive indicator is: $x_{i j k}^{i}=\left(x_{i j k}-x k_{\min } / x_{\max k}-x k_{\min }\right)$, and the processing method of the negative indicator is: $x_{i j k}^{\prime}=\left(x_{\min k}-x_{i j k} / x_{\min k}-x k_{\max }\right)$. After the standardized processing of the indicator, the value range of $x_{i j k}$ is $[0,1]$, which means the relative size is $x_{i j k}$.

Step 3. Calculate the weight of indicators. First, calculate the proportion of item $k$ of the $j$-th municipal district in the year $i$, and the formula is $y_{i j k}=x_{i j k}^{i} / \sum_{i} \sum_{j}^{x_{i j k}}$ $(i=1,2,3,10 ; j=1,2,3,16 ; k=1,2,3,29)$. Secondly, calculate the entropy value $E_{k}$ of the k-th index to obtain the formula: $E_{K}=-(1 / \theta) \sum_{i} \sum_{j} y_{i j k} \operatorname{In}\left(y_{i j k}\right)$. In it, we can see that $\theta>0$ and $\theta=\operatorname{In}(r n)$. Then, the information utility value $g_{k}$ of item $k$ is calculated: $g_{k}=1-E_{k}$. Finally, the weight $w_{k}$ of item $k$ is calculated: $w_{k}=g_{k} / \sum_{k} g k$.

Step 4. Calculate the comprehensive score of each district. The overall score is represented by $h_{i j}=\sum_{k} w_{k} x_{i j k}$ $(i=1,2,3,10 ; j=1,2,3,16 ; k=1,2,3,29)$. The result interval of the formula is $[0,1]$. To facilitate comparative analysis, the efficiency coefficient is used for unified treatment and the final comprehensive index is $H_{i j}=100 h_{i j}+50$. After optimization, the final score of each item is between 60 and 100 points.

4.2. Preliminary Analysis on the Comprehensive Index of Urban Subcenter Governance in Beijing. Based on the established governance evaluation index system of the Beijing subcenter, the entropy weight method was used to 
TABLE 2: Beijing urban subcenter governance comprehensive index score.

\begin{tabular}{|c|c|c|c|c|c|c|c|c|c|c|}
\hline & 2010 & 2011 & 2012 & 2013 & 2014 & 2015 & 2016 & 2017 & 2018 & 2019 \\
\hline Dongcheng district & 75.7 & 76.6 & 78.1 & 79.5 & 80.0 & 82.9 & 84.9 & 86.9 & 87.2 & 89.9 \\
\hline Xicheng district & 81.8 & 83.4 & 85.1 & 87.1 & 88.0 & 92.6 & 96.0 & 88.6 & 91.2 & 93.6 \\
\hline Chaoyang district & 78.7 & 77.9 & 79.6 & 79.5 & 80.4 & 80.2 & 83.1 & 84.0 & 83.3 & 86.6 \\
\hline Fengtai district & 69.2 & 68.5 & 69.5 & 69.3 & 69.9 & 69.2 & 71.2 & 72.7 & 72.3 & 74.0 \\
\hline Shijingshan district & 64.9 & 65.3 & 65.7 & 66.6 & 67.8 & 68.6 & 70.6 & 70.7 & 71.3 & 72.9 \\
\hline Haidian district & 87.2 & 87.3 & 88.7 & 88.1 & 90.6 & 90.0 & 97.0 & 95.7 & 93.7 & 94.5 \\
\hline Fangshan district & 63.8 & 63.2 & 64.4 & 65.3 & 65.4 & 66.8 & 68.8 & 70.6 & 69.6 & 71.4 \\
\hline Tongzhou district & 64.1 & 62.4 & 63.5 & 64.9 & 64.8 & 65.1 & 70.2 & 71.6 & 69.7 & 72.2 \\
\hline Shunyi district & 66.8 & 66.5 & 67.4 & 68.7 & 70.3 & 70.0 & 72.5 & 72.8 & 71.3 & 72.0 \\
\hline Changping district & 78.9 & 79.3 & 80.6 & 79.2 & 81.7 & 79.8 & 81.1 & 82.2 & 77.5 & 79.2 \\
\hline Daxing district & 64.1 & 62.7 & 63.8 & 64.7 & 67.1 & 68.1 & 69.4 & 73.1 & 71.9 & 72.8 \\
\hline Mentougou district & 65.3 & 66.2 & 66.9 & 68.4 & 67.8 & 68.7 & 71.7 & 73.4 & 71.6 & 73.4 \\
\hline Huairou district & 67.5 & 67.9 & 68.9 & 68.5 & 69.9 & 68.9 & 71.5 & 73.3 & 71.7 & 72.6 \\
\hline Pinggu district & 63.6 & 63.6 & 65.0 & 65.2 & 65.3 & 68.3 & 68.8 & 70.0 & 70.2 & 70.6 \\
\hline Miyun district & 63.9 & 64.1 & 64.8 & 66.2 & 66.4 & 66.8 & 69.0 & 69.9 & 70.1 & 72.9 \\
\hline Yanqing district & 67.5 & 68.4 & 68.4 & 69.1 & 69.6 & 68.7 & 71.5 & 74.1 & 71.2 & 73.1 \\
\hline
\end{tabular}

finally calculate the comprehensive index score of the Beijing subcenter governance over the years, as shown in Table 2. Among them, other municipal districts were taken as reference objects, and the data of Tongzhou District represented the score of the Beijing subcenter. Among them, other municipal districts were taken as reference objects, and the data of Tongzhou District represented the score of the Beijing subcenter; therefore, we have highlighted this group of data in bold in the table. And the final calculated score range is 62.4 to 97 .

With the help of geospatial analysis software ArgGIS, the visualization is shown as follows.

As can be seen from Table 2 and Figure 2, on the whole, the comprehensive index of subcenter governance in Beijing shows an increasing trend year by year, but there is still a certain gap between it and some municipal districts. Deputy city center in Beijing early in the development and construction, the development of the whole Beijing appears as the center of the typical diffusion model. The Dongcheng district and Xicheng district, which are the capital functioncore areas, gradually spread outward with a gradually decreased score in distance. It presents a situation of strong overall center, low surroundings, slightly stronger north, and a lower south pattern. As the deputy center of Beijing city develops gradually, it can be found that the center diffusion mode changes, which gradually shows a center vice center double pattern. Although the core capital area is still significantly higher than other areas, the overall distribution is gradually moving towards integration. Tongzhou District, in particular, has seen a leapfrog development. It can be preliminarily believed that under the promotion of the Beijing subcenter strategy, the systematization degree of the whole of Beijing is further improved. All parts are more closely connected, and it gradually jumps out of the "spread out" mode of center diffusion, and moves toward the pattern of two-center and even diversified development pattern of center and subcenter. However, in the current stage, the development of the whole of Beijing still shows a strong center attraction model, and even the rapid development of the center has caused a certain "inverse distribution" effect on the surrounding areas.

4.3. Analysis and Prediction of Governance Evolution Path of Urban Subcenter in Beijing. Based on the geographical visualization analysis in the above part, we find that the development speed of Tongzhou District shows a nonuniform growth. At the same time, on the whole, the development mode of the outermost part of Beijing has changed. To further analyze the evolution path of the governance of Beijing sub-urban center, the comprehensive index of Tongzhou District from 2010 to 2019 was selected for regression analysis, and the specific results are shown in Figure 3. It can be seen that the overall score of the comprehensive evaluation of the subcenter of the city shows a trend of rapid growth, while there is a very obvious leap-forward development in the middle. Through the fitting analysis of the linear regression model, it can be divided into two stages. The first stage was from 2010 to 2015. During this stage, the development of the Beijing subcenter (Tongzhou District) showed a rising trend with a slow rising speed. From 2015 to 2016, the subcenter of Beijing city (Tongzhou District) developed by leaps and bounds, and its comprehensive evaluation score was significantly improved. After that, it entered a faster development level and showed a trend toward highquality development. On May 27, 2016, General Secretary $\mathrm{Xi}$ Jinping chaired a meeting of the political bureau of the CPC central research deployment planning and construction of Beijing city deputy center and further promoted the development of Beijing-Tianjin-Hebei collaborative work. The planning deployment and policy supported at the national level have brought strong exogenous power to the development of Beijing sub-urban center and stimulated the leapfrog development of Beijing sub-urban center.

Based on the above analysis, the prediction analysis is as follows: 


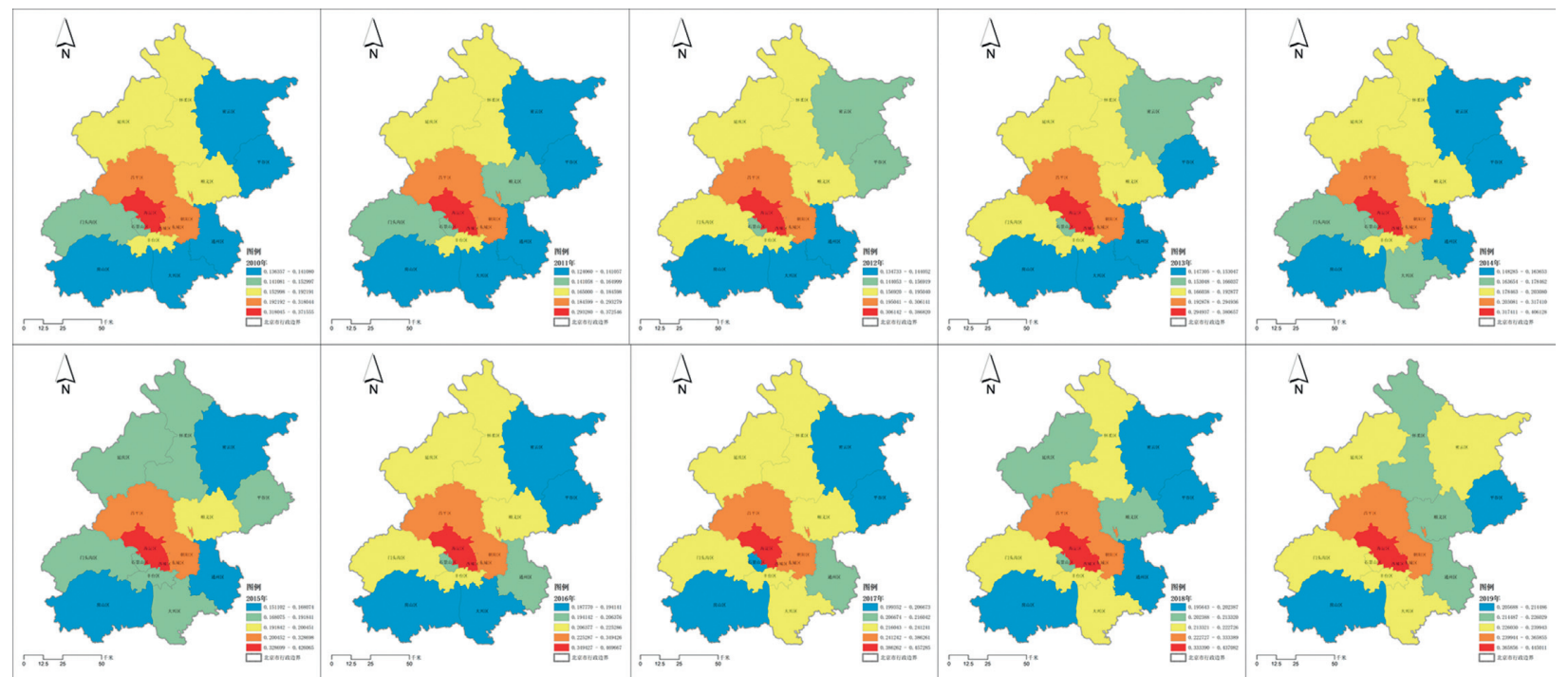

FIGURE 2: Distribution map of comprehensive index of urban subcenter governance in Beijing (years: 2010-2019).

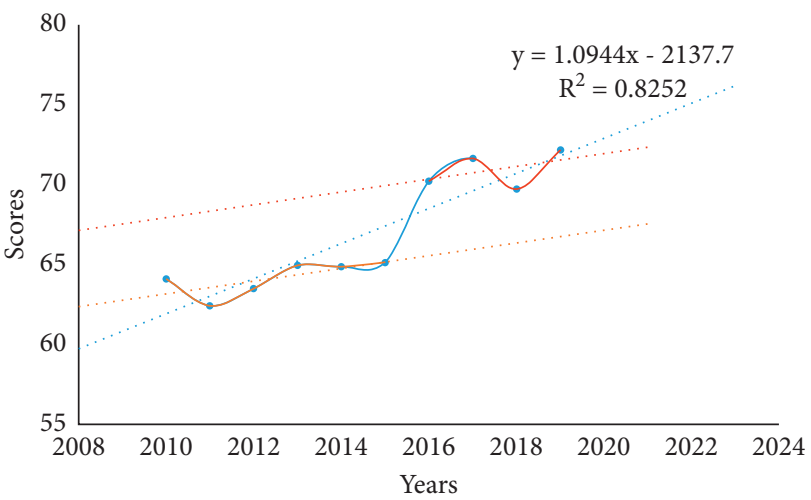

$\rightarrow$ Comprehensive evaluation score of urban sub center Overall forecast line of urban sub center Fitting line of urban sub center in the initial stage Fitting line of acceleration period of urban sub center

Figure 3: Regression analysis of comprehensive index of urban subcenter governance in Beijing.

(1) The subcenter of Beijing will realize the leapfrog development again. Policy support can bring strong impetus other than endogenous impetus, especially the series of major deployments by the CPC Central Committee, and The State Council, which will bring huge political policy dividend, resource dividend, and confidence dividend to the development of the Beijing subcenter. In particular, in 2021, The State Council will issue a series of major deployment and task arrangements, such as the Opinions on Supporting the High-quality Development of the Beijing subcenter, which will surely drive a new wave of the strong exogenous driving force.

(2) After major policy support, short-term exogenous power will gradually converse into the endogenous driving force of the development of the Beijing city center. At present, the governance level of Beijing's urban subcenter is relatively backward in the whole of Beijing. There is a big progress space. The policy after the leapfrog development of Beijing sub-city Center will enter the stable development of 5-10 years.

\section{Conclusion}

From the perspective of system theory and the evaluation of the development ability of the object of urban governance, this paper constructs the governance evaluation index system of the Beijing subcenter, which contains five subsystems including economic subsystem, social subsystem, cultural subsystem, ecological subsystem, and administrative subsystem, and 29 secondary indexes. After a comprehensive examination of panel data of Beijing's urban system during the subcenter construction period (2010-2019), a comprehensive evaluation of Beijing's subcenter (Tongzhou District) was conducted by using entropy method and a comparative analysis with other 15 municipal districts, and the following suggestions were put forward.

(1) To deal with the complex problems and challenges of Beijing suburban center, we must first strengthen the material foundation through development. Development is still the top priority of Beijing sub-urban center. But under the new situation, the development of Beijing vice center cannot follow the development patterns of the past. And, it must firmly build up the idea of high-quality development, put quality as the priority of urban development, take the lead in promoting the development of high-quality index systems, policy systems, standard systems, statistics systems, breakthrough performance evaluations, assessment system, etc.

(2) Innovation is the fundamental driving force for economic development. Especially in the new situation, the upgrading of urban economic 
development must rely on innovation. To build an important wing and become the strategic fulcrum of world-class urban agglomeration, Beijing suburban center must have certain economic strength and radiation ability. It does not necessarily need to become the city with the largest economic volume, but at least it should achieve the status of "decisive." In 2017, the GDP of the first urban area of the four first-tier cities-Beijing, Shanghai, Shenzhen and Guangzhou-accounted for more than 20 percent of the total GDP of their cities and more than 4 percent of the total economic output of their urban agglomerations. The GDP of the functional core area of the Capital also accounts for more than 20 percent of Beijing and 7.5 percent of the Beijing-Tianjin-Hebei metropolitan area. However, The GDP of Tongzhou District only accounts for 2.7 percent of Beijing and 0.9 percent of The Beijing-Tianjin-Hebei urban agglomeration. The economic size of Tongzhou District is too small, which plays a weak radiating and driving role in urban and regional development and has a large gap with its target positioning. We should continue to take innovation as the primary driving force, focus on integrated development and sound interaction, apply major scientific and technological innovations, seize the strategic vantage point for future development, and promote the innovationdriven development of the Beijing-Tianjin-Hebei city cluster.

(3) Improve the comprehensive carrying capacity of cities through urban hardware and software construction, and promote the quality and balanced development of urban public services. The low quality of public service is an important factor that makes the comprehensive score of subcenter governance in Beijing lower than that of other municipal districts. Therefore, we need to take the initiative to adapt to changes in population size and structure, and implement some key projects every year to make up for gaps and weaknesses in public services. Strengthen the resource pooling and promote the balanced distribution of quality public service facilities among groups. In education, we will increase preschool education resources, improve the system of compulsory education and high school education, and comprehensively implement qualityoriented education. We will complement and improve basic education facilities, expand the supply of degrees, and constantly optimize the allocation of educational resources according to the positioning and development needs of various groups. We will focus on improving primary schools and childcare facilities in areas lacking basic education facilities such as old urban areas. Establish a hand-in-hand support mechanism for high-quality schools in central urban areas and primary and secondary schools in urban subcenters, form an education group brand, and speed up the construction of a some key projects such as Beijing School, Beihai Kindergarten, and Huangchenggen Primary School.
(4) Achieve regional coordinated development on a larger spatial scale. The 155 square kilometers of the Beijing subcenter are included in the 906 square kilometers of Tongzhou District. Only by planning the subcenter based on the whole area of Tongzhou can the development gap be prevented and the necessary development level is guaranteed. In practice, it is necessary to coordinate the integrated and coordinated development of "city" and "township," with the construction of small towns with special characteristics as the starting point to form a new pattern of urbanization with the interconnected functions, with the city leading the township, and with the urban and rural coprosperity. Nearly half of the subcenter is the old city. There will be two levels and two faces of a subcenter if it is not handled well. The construction of the subcenter must not only build the new city but also improve the old city. The focal point is the ecological restoration and urban repair of the old city so as to promote the deep integration of the space, function, and society of new city and old city.

\section{Data Availability}

The data used to support the findings of this study are available from the corresponding author upon request.

\section{Conflicts of Interest}

The authors declare that they have no conflicts of interest.

\section{Authors' Contributions}

Liexuan Wang was involved in conceptualization, resources, and methodology; Kunsheng Wang was concerned with the supervision and roject administration; and Huajin Huang was responsible for original draft and reviewed and edited the manuscript.

\section{References}

[1] X. Wu and M. Wang, "Urban governance: a literature review," Reference to Economic Research, vol. 30, no. 30, pp. 53-61, 2016.

[2] W. Liu, S. X. Lei, and S. Y. Zhang, "Study on quantitative evaluation on management modernization of Tongzhou subcenter city in Beijing," in Proceedings of the 2017 Global Conference on Mechanics and Civil Engineering (GCMCE 2017), pp. 195-201, Atlantis Press, Guangzhou, China, June 2017, https://www.atlantis-press.com/proceedings/gcmce-17.

[3] K. Yu, "Evaluation framework of Chinese governance," Comparison of Economic and Social Systems, vol. 6, no. 06, pp. 1-9, 2008.

[4] Y. Zhang, P. Lin, and H. Liu, "Empirical research on the governance maturity of the digital cities in China," China Science and Technology Forum, no. 05, pp. 70-76, 2010.

[5] Y. Guo and W. Cheng, "Measuring governance level of Chinese localities: empirical study in five Chinese cities," Urban Development Studies, vol. 17, no. 12, pp. 113-118, 2010. 
[6] C. Lin and F. Mao, "Analysis of financial input and urban governance performance: a case study of Jiangsu and Zhejiang urban agglomerations," Finance and Trade Economics, vol. 12, no. 12, pp. 45-52, 2012.

[7] J. Wang and H. Xia, "Evaluation of governance capacity of five regional central cities," Open Herald, vol. 3, no. 03, pp. 16-19, 2015.

[8] J. Han, H. Liang, K. Hara, M. Uwasu, and L. Dong, "Quality of life in China's largest city, Shanghai: a 20 year subjective and objective composite assessment," Journal of Cleaner Production, vol. 173, pp. 135-142, 2018.

[9] K. Wanghe, X. Guo, X. Luan, and K. Li, “Assessment of urban green space based on bio-energy landscape connectivity: a case study on Tongzhou district in Beijing, China," Sustainability, vol. 11, no. 18, p. 4943, 2019.

[10] K. Wang, L. Hu, A. Zheng, X. Mao, X. Miao, and K. Ma, "Measurement engineering-a preliminary study on the theoretical methods and techniques of fine management," Mathematics in Practice and Cognition, vol. 41, no. 24, pp. 54-60, 2011.

[11] Y. Shen, K. Wang, X. Ma, L. Hu, and Y. Xu, "Construction and analysis of science and technology power evaluation system," Journal of Chinese Academy of Sciences, vol. 35, no. 05, pp. 593-601, 2020.

[12] S. Lehmann, "Lessons from Europe for China? new urban subcentres for a polycentric network city," Journal of Green Building, vol. 5, no. 1, pp. 88-100, 2010.

[13] C. E. Shannon, "A mathematical theory of communication," Bell System Technical Journal, vol. 27, no. 3, pp. 379-423, 1948. 